\title{
СИНДРОМ ДОНАХЬЮ: КЛИНИЧЕСКИЙ СЛУЧАЙ
}

\author{
М.А. Меликян', Е.В. Гаузун ${ }^{2}$, Н.Г. Чепурко ${ }^{2}$, А.С.. Киреева ${ }^{2}$ \\ 'ФГБУ «НМИЦ Эндокринологии» МЗ РФ г. Москва \\ 2ГАУЗ АО «Амурская областная детская клиническая больнича», г. Благовещенск
}

ВВЕДЕНИЕ: представлен клинический случай редкого синдрома врожденного гиперинсулинизма у ребенка с отягощенным наследственным анамнезом. Синдром Донахью у ребенка был заподозрен на основании характерной клиническо-лабораторной картины: множественные стигмы дизэмбриогенеза, атрофия подкожно-жирового слоя, вариабельность гликемии на фоне значительно повышенного уровня инсулина и с-пептида, гипертрофической кардиомиопатией. В дальнейшем данный синдром у пациента был подтвержден молекулярно-генетическим исследованием. Ребенок обследован в ФГБУ «НМИЦ эндокринологии», консилионно назначена патогенетическая терапия инсулиноподобным фактором роста 1.

КЛИНИЧЕСКИЙ СЛУЧАЙ: МальчИК Н. В Возрасте 1 мес поступил в ГАУЗ АО «АОДКБ» Из перинатального центра с диагнозом: «Неонатальный сахарный диабет». Ребенок от 6 беременности (1,2 - мед. аборт; 3 - роды в 2013 г. мальчик, умер в 4,5 мес, (наследственная болезнь обмена? Гипертрофическая кардиомиопатия), 4 - роды в 2015г, мальчик здоров; 5 - роды, девочка умерла в 3,5 мес (гипертрофическая кардиомиопатия, Лепречаунизм? Гиперинсулизм). Родители генетиком консультированы, не обследованы. Данная беременность: Роды 4, в срок 37 нед, оперативные. Масса при рождении 1788 г, длина тела - 43 см. По Апгар 8/8 баллов. После рождения выявлена гипергликемия до 7,6 ммоль/л на фоне парентерального питания, в динамике глюкоза крови повышалась эпизодически до 13,3 ммоль/л, с возраста 27 дней стойкая гипергликемия до 24,7 ммоль/л, в дополнительном исследовании гиперинсулинемия (25,7 мкЕд/мл), повышен уровень С-пептида (5291 пмоль/л). Начато титрование доз инсулина в/в под контролем глюкозы крови. Объективный статус: Состояние ребенка средней тяжести, компенсировано. Мальчик пониженного питания, подкожно-жировой слой отсутствует. Кожные покровы смуглые, сухие, гипертрихоз. Множественные стигмы дизэмбриогенеза: преобладание мозгового отдела черепа над лицевым, «лицо эльфа», шаровидные глаза, микрогнатия, низкое расположение и увеличение ушных раковин, запавшая переносица, нос увеличен в размерах, гипертрофия сосков, «лягушачий» живот, высокое небо. Гемодинамически стабилен, шум выслушивается систолический на верхушке. ЧСС 148 в мин. Эндокрино-

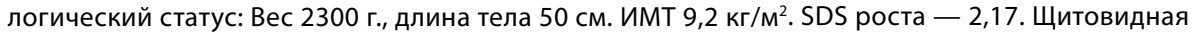
железа 0 степени. SDS ИMT-5,13. Половые органы сформированы по мужскому типу. По Таннер 1. В обследовании: анемия легкой степени, микроальбуминурия до 66,9 мг/л, повышен тестостерон до 11,2 нмоль/л, ЛГ 1,88 МЕ/мл, ФСГ 0,38 МЕ/мл, Гликированный гемоглобин 5,11\%. СТГ - 3.1 нг/мл. В динамике нарос уровень С-пептида до 43484 пмоль/л. По результатам ТМС выявлено повышение тирозина, в контроле показатели в норме. ЭХО-КГ: Гипертрофия стенок ЛЖ с повышением сократительной способности миокарда. Недостаточность МК с регургитацией до 2 степени без изменения створок. Ускорение кровотока на АО за счет признаков подклапанного стеноза деформированной МЖП. Консультирован кардиологом: симметричная, концентрическая, гипертрофическая кардиомиопатия, МАРС- ООО, коронаро-легочная фистула? HK II А, угрожаем по синдрому внезапной смерти. В терапии рекомендовано: диуретик и бета1-адреноблокатор. В динамике состояние ребенка стабильное, в весе прибавлял плохо. В связи с развитием гипогликемии инсулин отменен, наблюдалась вариабельность гликемии от 1.8 до 11.3 ммоль/л, на фоне энтерального питания смесью. От установки назогастрального зонда и непрерывного кормления смесью мать отказалась. Была проведена телемедицинская консультация в ФГБУ «НМИЦ эндокринологии», заподозрен синдром Донахью. По результатам молекулярно-генетического исследования в 4 экзоне гена INSR выявлен вариант: нуклеотидная замена NM_000208.3: chr19-7174702-A-G, c.1015T>C (p.Cys339Arg) в гомозиготном состоянии. Госпитализирован в ФГБУ «НМИЦ Эндокринологии», где ребенок был переведен непре- 


\section{СБОРНИК ТЕЗИСОВ}

XVII Российская научно-практическая конференция детских эндокринологов «Достижения науки в практику детского эндокринолога»

рывное парентеральное питание, консилионно была назначена патогенетическая терапия мекасермином (препарат не зарегистрирован в РФ), на фоне терапии достигнута эугликемия, ребенок стал прибавлять в весе. Прогноз неблагоприятный. Рекомендовано паллиативное лечение. Выписан на амбулаторное лечение.

ЗАКЛЮчЕНИЕ: Синдром Донахью (Лепречаунизм) - редкое аутосомно-рецессивное заболевание, ассоциированное с мутациями в гене рецептора инсулина (INSR). Частота заболевания, по данным литературы, 1 случай на 1000000 новорожденных. Описан синдром впервые в 1948 г. и в 1954 г. В РФ первый случай данного заболевания описан в 2016 г.. Клинически для синдрома Донахью характерно: задержка внутриутробного развития, плохая прибавка в весе, отсутствие подкожно-жирового слоя, атрофия мышц, гиперпигментация кожи, гипертрихоз. Так же у таких детей наблюдаются множественные стигмы дизэмбриогенеза: аномально большие, низко посаженные и плохо развитые уши; необычно плоская переносица; большой нос, большие толстые губы; макростомия, гипертелоризм. Лабораторно синдром ассоциируется со значительным повышение базального инсулина и С-пептида. Лечение симптоматическое, для патогенетического лечения применяется ИФР 1. Прогноз крайне неблагоприятный: большинство пациентов погибают в течение первых двух лет жизни на фоне тяжелой гипотрофии и рецидивирующих инфекций. Приведенный клинический случай демонстрирует особенности течения синдрома Донахью у ребенка. Ранняя генетическая верификация данного синдрома необходима для проведения дифференциальной диагностики с другими формами сахарного диабета, определения тактики ведения таких пациентов. Важное место занимает медико-генетическое консультирование, касающееся дальнейшего планирования семьи.

КЛЮЧЕВЫЕ СЛОВА: СИндром Донахью; лепречаунизм; врожденный гиперинсулинизим; кардиомиопатия; мекасермин. 